\title{
Density-functional theory study on the arrangement of adsorbed formate molecules on $\mathrm{Cu}(110)$
}

\author{
N. Atodiresei, K. Schroeder, and S. Blügel \\ Institut für Festkörperforschung, Forschungszentrum Jülich, D-52425 Jülich, Germany \\ (Received 2 February 2006; revised manuscript received 17 November 2006; published 9 March 2007)
}

\begin{abstract}
The interaction of formate molecules with the $\mathrm{Cu}(110)$ surface is investigated using density-functional theory calculations. We find that in the most stable structures for low and high coverage, the formate molecules are sitting perpendicular to the $\mathrm{Cu}(110)$ surface, and they are adsorbed in a bridge position, i.e., the $\mathrm{O}-\mathrm{C}-\mathrm{O}$ group forms a bridge between two $\mathrm{Cu}$ atoms. Other tested configurations are less stable by at least $0.45 \mathrm{eV}$ per formate molecule. In the case of an oxygen-precovered $\mathrm{Cu}(110)$ surface with high formate coverage [two molecules in a $(2 \times 2)$ unit cell] we find a very similar adsorption geometry. We find an attractive interaction between adsorbed formate molecules on the copper surface. Our results are consistent with experimental results by scanning tunneling microscopy and photoelectron diffraction.
\end{abstract}

DOI: 10.1103/PhysRevB.75.115407

PACS number(s): 71.15.Mb, 71.15.Nc

\section{INTRODUCTION}

Surface reactions involving organic molecules have attracted increasing attention recently. Apart from their traditional use in a vast number of economically important surface processes such as catalysis in chemical production, corrosion, and the fabrication of computer chips or magnetic storage devices, the behavior of biomaterials and the organic functionalization of the metallic surfaces have important applications. ${ }^{1}$ In addition, electronic transport involving organic molecules adsorbed on metal surfaces is considered a promising pathway to nanoelectronic devices.

Within such a technological complex, it is clear that the development of future organic and/or inorganic interfaces is critically dependent on establishing a fundamental understanding of the various bonding mechanisms and lateral interactions that govern the orientation, conformation, and two-dimensional organization of these molecules at the surface.

Recent developments have enabled the chemistry field of surface science to progress from the study of simple adsorbates to the investigation of bigger and more complicated molecules, e.g., organic acids and amino acids. The carboxyl group is a well-known anchoring group for the chemical binding to metal surfaces of a large variety of organic molecules. ${ }^{1-4}$

From the theoretical point of view, to understand the binding to the metal surface of the simplest molecule that contains the carboxyl group (which is the formic acid) is a first step in the treatment of more complex molecular structures. On the other hand, the adsorption of formic acid on copper single-crystal surfaces, in particular, $\mathrm{Cu}(110)$ surface, has also attracted considerable attention due to the identification of formate as a key stable intermediate in methanol synthesis, which is carried out commercially using copper-based catalysts. ${ }^{6}$

The binding and ordering of molecules on surfaces is, in general, controlled by a delicate balance between competing molecule-substrate and intermolecular interactions. The adsorption on metal surfaces may change the geometrical and electronic properties of the molecule and the exact adsorption conformation may play an important role in the electron transfer from the metal to the molecule. A detailed insight into the binding geometries and the ordering of the molecules on surfaces and the specificity of the interactions that occur between anchored molecules can be obtained by performing $a b$ initio calculations. The first question concerns the adsorption geometry and the atomic positions. The next step is understanding the electronic structure and the hybridization of orbitals in the formation of the bonds.

\section{PREVIOUS EXPERIMENTAL RESULTS}

Formic acid adsorption has been studied experimentally on both clean and oxygen-precovered surfaces of copper. At elevated temperatures $\left(300-450{ }^{\circ} \mathrm{C}\right)$, formate molecules are chemically adsorbed on the $\mathrm{Cu}$ surface by dehydrogenation (on a clean surface) or the release of water (on an oxygenprecovered surface) of the formic acid. ${ }^{7-10}$ To determine the formate adsorption structures, several experimental methods have been used: ${ }^{7,11-15}$ near-edge x-ray-absorption fine structure (NEXAFS) spectroscopy, surface-extended x-rayabsorption fine structure (SEXAFS) spectroscopy, lowenergy electron diffraction (LEED), Auger electron spectroscopy, temperature-programed desorption, scanning tunneling microscopy (STM), reflection-absorption infrared spectroscopy, and in situ infrared reflection-absorption spectroscopy.

With some of the experimental methods, it was difficult to determine how the formate molecules are chemisorbed on the copper surface. The distinction between an upright and tilted geometry, or between bidentate geometry (oxygen binds to two copper atoms ${ }^{11,13}$ ) and monodentate geometry (oxygen binds to a single copper atom ${ }^{12,13}$ ) cannot be made unambiguously. Some NEXAFS, SEXAFS, and STM experiments have suggested specific geometries: ${ }^{12,13}$ the molecules are adsorbed with their molecular plane perpendicular to the metal surface, and the molecules are arranged in rows with the plane formed by the carboxylate group along the [1 $\overline{1} 0]$ direction.

Experiments suggest that the formate molecules form a $(2 \times 2)$ and $(3 \times 1)$ superstructure on the $\mathrm{Cu}(110)$ surface, ${ }^{13}$ which by anealing up to $400 \mathrm{~K}$ regenerate in well-ordered 
TABLE I. Parameters used to construct the pseudopotential projectors. For the PAW pseudopotentials, the cutoff radii $\left(r_{\text {cut }}\right)$ and reference energies $\left(E_{\text {ref }}\right.$ in Ry) are listed. The first line refers to the eigenvalues of the bound states for the respective $l$ channel; the second line refers to the specific energies for the unbound states used to construct the second projector for each $l$ channel. The radii of the partial-core correction $\left(r_{p c c}\right)$ are $\mathrm{C}$ 1.0, $\mathrm{O} 1.1$, and $\mathrm{Cu} 2.1$. All the radii are in $a_{B}(0.529177 \AA)$.

\begin{tabular}{|c|c|c|c|c|c|c|c|c|}
\hline \multirow[b]{3}{*}{ Atom } & \multicolumn{8}{|c|}{ Channel } \\
\hline & \multicolumn{2}{|c|}{$s$} & \multicolumn{2}{|c|}{$p$} & \multicolumn{2}{|c|}{$d$} & \multicolumn{2}{|c|}{$f$} \\
\hline & $r_{\text {cut }}$ & $E_{\text {ref }}$ & $r_{\text {cut }}$ & $E_{r e f}$ & $r_{\text {cut }}$ & $E_{r e f}$ & $r_{c u t}$ & $E_{r e f}$ \\
\hline \multirow[t]{2}{*}{$\mathrm{C}$} & 1.10 & -1.0098 & 1.10 & -0.3887 & & & & \\
\hline & 1.10 & -0.7000 & 1.10 & -0.7000 & 1.10 & -0.3000 & & \\
\hline \multirow[t]{2}{*}{$\mathrm{O}$} & 1.10 & -1.7577 & 1.10 & -0.6643 & & & & \\
\hline & 1.10 & -0.1000 & 1.10 & -0.0900 & 1.10 & -0.4000 & & \\
\hline \multirow[t]{2}{*}{$\mathrm{Cu}$} & 2.10 & -0.32622 & 2.10 & -0.0518 & 2.10 & -0.3831 & & \\
\hline & 2.10 & -0.3000 & 2.10 & -0.0500 & 2.10 & -0.2300 & 2.10 & -0.1000 \\
\hline
\end{tabular}

$(2 \times 2)$ and $(4 \times 1)$ formate structures..$^{8,10,13-16}$ At low coverage, there is just one molecule in the unit cell, whereas at high coverage, the unit cell contains two molecules. At high coverage on the clean surface, the formate molecules form small domains and to some extent are randomly distributed. It is assumed that there are repulsive intermolecular interactions between the molecules in the [001] direction, which increase their mobility at the surface and prevent the observation of an ordered LEED pattern or clearly interpretable STM images. ${ }^{13}$ According to the experiments, the formate adsorption structure on the clean $\mathrm{Cu}(110)$ surface has similarities to the $(2 \times 2)$ formate structure that has been reported for the formic acid adsorption on the $0.5 \mathrm{ML}$ (monolayer) oxygen-precovered copper surface. In the last case, the $(2$ $\times 2$ ) formate structure can be imaged with STM with good resolution, indicating that the formate molecules are much better ordered and more localized than on the clean surface. It seems that the repulsive interaction between the molecules can be overcome in the case of the oxygen-precovered surface. The higher formate coverage is enabled through the energetically favorable reaction of formic acid deprotonation by the preadsorbed oxygen. ${ }^{13,16}$ In this case, the carboxylic hydrogen leaves the surface not as $\mathrm{H}_{2}$ but rather as $\mathrm{H}_{2} \mathrm{O}$. There are two $\mathrm{O}$ atoms in the precovered oxygen $(2 \times 2)$ unit cell. One is used for the formation of $\mathrm{H}_{2} \mathrm{O}$, while the second one remains in the $(2 \times 2)$ unit cell (i.e., $0.25 \mathrm{ML})$.

Several theoretical calculations using $a b$ initio densityfunctional theory as well as semiempirical methods have been reported in the literature ${ }^{17,18}$ to determine the adsorption geometry of a formate molecule on the $\mathrm{Cu}(110)$ surface. All of them are based on the cluster approach: a cluster of eight to ten copper atoms is used to model the metal surface, where the copper atoms are kept at their ideal bulk positions. These methods take into account just one formate molecule on the surface, and they can only describe the local structure of the molecule-metal surface system at very low coverage. With these methods, no information concerning the intermolecular interactions can be obtained. In the present work, several geometries and different coverages of the formate adsorption on the $\mathrm{Cu}(110)$ surface are optimized using the supercell approach. The results obtained with this method can be compared with the cluster approach at low coverage. The supercell approach has the advantage of better simulating the real system because it takes into account a real infinite surface and also includes the interactions between the molecules when the coverage increases.

\section{THEORETICAL METHOD}

All calculations are based on the density-functional theory (DFT) in the generalized-gradient approximation PerdewBurke-Etrnzerhof (GGA-PBE) functional. ${ }^{19}$ In order to solve the Kohn-Sham equations for the ground state of the valence electrons, we used an energy-minimization scheme based on the pseudopotential plane-wave (PPW) method. This PPW method approximates the crystal surface with the attached molecules by periodically arranged large supercells, and uses plane waves to expand the electronic wave functions. This has the advantage of allowing band-structure methods to be used in determining the electronic structure, and total energies and forces on the atoms to be calculated without difficulty for arbitrary arrangements of the atoms in the supercell.

Our ESTCOMPP program ${ }^{20,21}$ can handle norm-conserving Kleinman-Bylander (KB) pseudopotentials ${ }^{22}$ and projectoraugmented wave (PAW) multiprojector pseudopotentials ${ }^{23}$ to describe the electron-ion interaction. For the $\mathrm{H}$ atom a KBlocal potential is used for the $s$ electron. For $\mathrm{C}$ and $\mathrm{O}$, the $2 s$, $2 p$ valence electrons, and for $\mathrm{Cu}$, the $4 s, 4 p$ valence electrons as well as the $3 d$ electrons are treated explicitly with PAW pseudopotentials. Partial-core correction was used for $\mathrm{C}, \mathrm{O}$, and $\mathrm{Cu}$. The cutoff radii and reference energies used to generate the projectors, and the radii of the partial-core correction are listed in Table I. The charge augmentation within the PAW method is done in the sphere with the largest cutoff radius (augmentation sphere). For the Brillouin-zone integration, we used $12 \vec{k}$ points in the irreducible part generated with a Monkhorst-Pack scheme. ${ }^{24}$ This is equivalent to 6 $\times 6 \times 6 \vec{k}$ points for a $\mathrm{Cu}$ bulk calculation. We used a plane- 
TABLE II. The bond lengths and $\mathrm{O}-\mathrm{C}-\mathrm{O}$ angle for the ${ }^{2} B_{2}$ state of a free formate radical.

\begin{tabular}{lccc}
\hline \hline & This work & Ref. 25 & Ref. 31 \\
\hline & & Bond length $(\AA)$ & \\
$\mathrm{CH}$ & 1.140 & 1.095 & 1.100 \\
$\mathrm{CO}$ & 1.247 & 1.261 & 1.257 \\
& & Angle $\left(^{\circ}\right)$ & \\
OCO & 110.87 & 111.6 & 111.50 \\
\hline \hline
\end{tabular}

wave cutoff of $25 \mathrm{Ry}$, which is required for the convergence of all PAW pseudopotentials.

\section{RESULTS AND DISCUSSION}

In order to calculate the changes due to the adsorption of formate on the $\mathrm{Cu}(110)$ surface (binding energy and change of geometry), we first optimized the structures of the formate (free radical) molecule and of the clean $(1 \times 1) \mathrm{Cu}(110)$ surface. The obtained results are comparable with theoretical data reported in the literature and with experimental results. ${ }^{17,18,25}$ Then we used these relaxed coordinates of the molecule and copper surface as starting positions in the molecule-surface calculations and relaxed the combined system to the minimum-energy configuration for several adsorption geometries. The obtained results are discussed in the following.

\section{A. Formate free radical}

The electronic and geometrical structures of the formate radical have been optimized using the GGA-PBE functional ${ }^{19}$ for the exchange correlation. The molecule has been placed in a cubic box with $a=8.5 \AA$. To check the convergence, several additional calculations have been done: a larger box with $a=18.5 \AA$ using gamma-point and larger $k$-point sets (up to $3 \times 3 \times 3$ ) with or without $C_{2 v}$ symmetry.
All calculations yield the same structure within a $10^{-3} \AA$ margin of error for the bond lengths. The bond lengths and $\mathrm{O}-\mathrm{C}-\mathrm{O}$ angle are given in Table II. Our optimized geometry and calculated electronic levels reproduce well those reported in the literature for the ${ }^{2} B_{2}$ state of the free formate radical. ${ }^{17,18,25-32}$

\section{B. Clean $\mathrm{Cu}(110)$ surface}

We optimized the structure of the $(1 \times 1) \mathrm{Cu}(110)$ surface using 7 and $13 \mathrm{Cu}$ layers and considering a vacuum layer of 9.51 and $19.02 a_{B}$, respectively. We used a $3 \times 12 \times 17 \vec{k}$-point set in the irreducible part of the Brillouin zone and a cutoff energy of $25 \mathrm{Ry}$. The results of the interlayer relaxations for this surface are in good agreement with the experimental data and other calculations reported in the literature. In Table III the results are summarized. To our experience, the radius of the partial-core correction $\left(r_{p c c}\right)$ is of great importance in obtaining the proper relaxations of the copper surface. A large $r_{p c c}$ will induce small relaxations (sometimes in the wrong direction) and a small $r_{p c c}$ will produce quite large relaxations. We optimized the $r_{p c c}$ of copper so that our relaxations are in very good agreement with those obtained through all-electron calculations. ${ }^{33}$

\section{Formate $\mathrm{Cu}(110)$ surface systems}

All GGA-PBE calculations of formate molecules adsorbed on the $\mathrm{Cu}(110)$ surface have been performed using an inversion-symmetric slab containing five copper layers. The unit cell has the dimensions $4 a \sqrt{2}$ (perpendicular to the surface) and $2 a, a \sqrt{2}$ (parallel), with $a=3.641 \AA$ being the theoretical bulk lattice constant of fcc $\mathrm{Cu}$. This results in a distance of $11.53 a_{B}$ between the hydrogen atoms of the formate molecules on opposite surfaces. An energy cutoff of $25 \mathrm{Ry}$ and a $1 \times 3 \times 4-k$ point set have been used.

In the calculated structures, all atoms except the innermost $\mathrm{Cu}$ layer have been allowed to relax without any constraint until the forces on the atoms were less than $1 \mathrm{mRy} / \mathrm{a} . \mathrm{u}$. We did not use any special symmetries, except

TABLE III. In this work $(\mathrm{tw})$ the interlayer relaxations $\left(\Delta_{i j}\right)$ of the the clean $\mathrm{Cu}(110)$ surface are given in $\%$ relative to the ideal bulk terminated surface. The experimental results (Ref. 5) are for $\Delta_{12}=-3.0$ to -10.0 and $\Delta_{23}=0.0$ to +8.0 . In line 3 the vacuum thickness $\left(a_{B}\right)$ above the surface is listed, and in line 4 the number of copper layers used in calculations.

\begin{tabular}{|c|c|c|c|c|c|c|c|c|}
\hline & \multicolumn{4}{|c|}{ LDA } & \multicolumn{4}{|c|}{ GGA } \\
\hline & \multicolumn{4}{|c|}{ tw } & Ref. 34 & tw & Ref. 33 & Ref. 35 \\
\hline 3 & \multicolumn{2}{|c|}{9.51} & \multicolumn{2}{|c|}{19.02} & & 19.02 & & 14.6 \\
\hline 4 & 7 & 13 & 7 & 13 & & 7 & 13 & 6 \\
\hline$\Delta_{12}$ & -11.00 & -11.07 & -11.46 & -11.42 & -9.30 & -11.01 & -9.73 & -10.08 \\
\hline$\Delta_{23}$ & +3.59 & +3.72 & +3.38 & +3.39 & +2.08 & +3.60 & +3.63 & +5.30 \\
\hline$\Delta_{34}$ & -1.69 & -2.14 & -1.99 & -2.32 & +1.10 & -1.16 & -1.16 & +0.10 \\
\hline$\Delta_{45}$ & & -0.39 & & -0.95 & & & +0.39 & \\
\hline$\Delta_{56}$ & & -0.98 & & -1.02 & & & -0.08 & \\
\hline$\Delta_{67}$ & & -0.87 & & -1.12 & & & +0.14 & \\
\hline
\end{tabular}


the inversion symmetry of our supercells. The relative energies of all configurations and the bond lengths in the calculated configurations are presented in the next tables. The $\mathrm{Cu}-\mathrm{O}$ distances larger than $3.0 \AA$ are not listed. A general observation is that in all calculated configurations (for different coverages of the formate molecules) the most stable ones contain only the molecules in bridge position with each $\mathrm{O}$ binding to one $\mathrm{Cu}$ atom.

\section{Low formate coverage on $\mathrm{Cu}(110)$ surface}

In the case of low coverage [one molecule in $(2 \times 2)$ unit cell], two of the most probable configurations have been optimized. In one configuration, the oxygen atoms are sitting on top of the copper surface atoms. This is the so-called bridge position (the carboxylate group, $\mathrm{OCO}$, is a bridge between two $\mathrm{Cu}$ atoms), where each of the oxygen atoms is forming one single bond with a copper atom (see Fig. 1). In the second configuration, the molecule is bound in a socalled top position ( $\mathrm{C}$ on top of a $\mathrm{Cu}$ atom), where each of the oxygen atoms is sitting on the surface between two copper nearest-neighbor atoms.

Atomic structure and energetics. The energy of the bridge position is $0.45 \mathrm{eV}$ lower than that of the top position, which makes it more stable. This can be explained by the stronger interaction of the oxygen and copper atoms indicated by the much shorter $\mathrm{O}-\mathrm{Cu}$ distances in the bridge position. The oxygen atoms are bound to the $\mathrm{Cu}(110)$ surface in a monodentate geometry (each oxygen of the carboxylic group binds to a single copper atom). Due to the copper-oxygen interaction for both configurations, the $\mathrm{O}-\mathrm{C}-\mathrm{O}$ angle is larger than for the single formate free radical $\left(128.4^{\circ}\right.$ for bridge, $125.3^{\circ}$ for top, and $110.8^{\circ}$ for free radical).

The relaxations of the copper atoms of the first layer depend on the existence of $\mathrm{O}-\mathrm{Cu}$ interactions (see Table IV). When the formate molecule is adsorbed in the bridge position, the copper atoms that are not bonded directly to the oxygen atoms show similar inward relaxations as on the clean $\mathrm{Cu}(110)$ surface. In contrast, when the relaxation of the copper atoms that form bonds with the oxygen atoms is very small, the positions of these atoms are close to unrelaxed ideal surface positions. When formate is adsorbed in the top position, each oxygen atom of the molecule binds with two nearest-neighbor copper atoms. The $\mathrm{O}-\mathrm{Cu}$ bond distances are larger and the relaxations of the copper atoms are quite small, i.e., the positions of the copper surface atoms are close to the ideal unrelaxed $\mathrm{Cu}(110)$ surface.

Comparison to literature. The molecular geometries and the $\mathrm{Cu}-\mathrm{O}$ bonds calculated in this work agree well with the theoretical results ${ }^{17,18}$ reported in the literature and the experimental data. ${ }^{12}$ The theoretical results in the literature are for the bridge position of a single formate molecule using the cluster approach and the DFT, restricted Hartree-Fock, and semiempirical theoretical approaches. ${ }^{17,18}$ In the reported DFT calculation, a localized basis set and the B3LYP hybrid functional ${ }^{36}$ for the exchange correlation have been used.

In the literature, experimental data and theoretical calculations are reported for organometallic complexes of $\mathrm{Cu}^{1+}$ with formic acid and diformate molecules. In these complexes, the oxygen atoms bind in monodentate geometry to
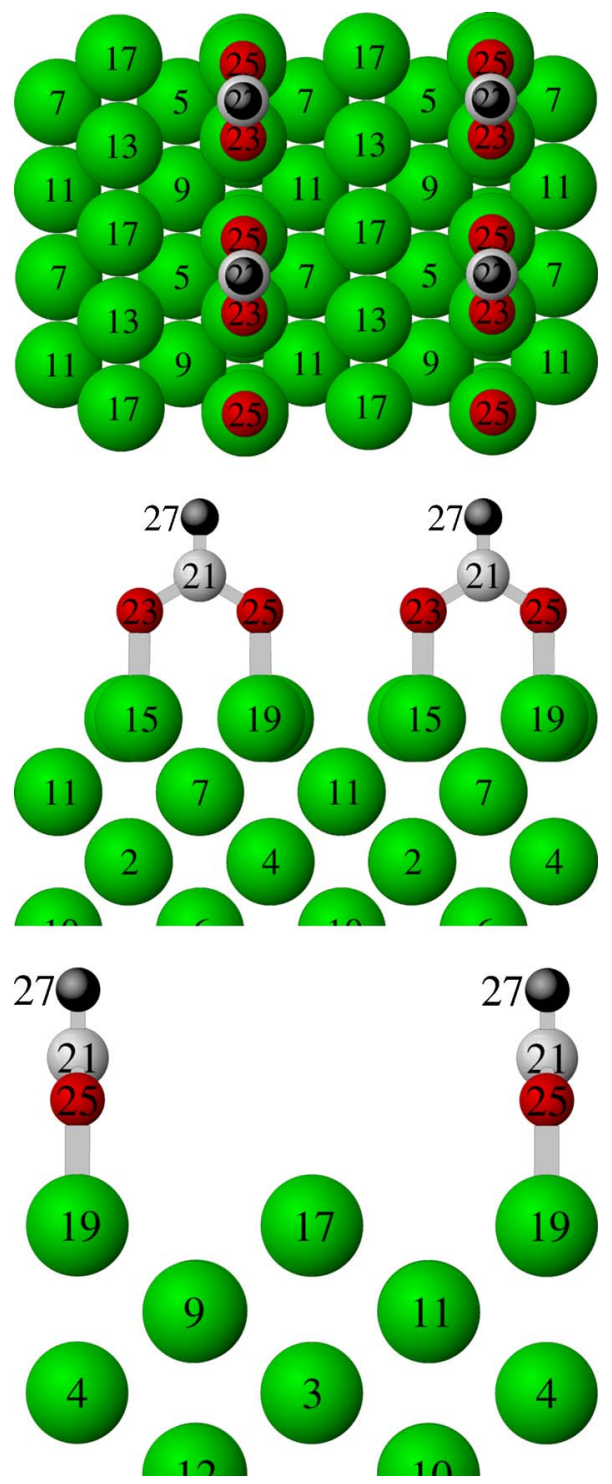

FIG. 1. (Color online) Adsorption geometry of one formate molecule in a $(2 \times 2)$ unit cell on a clean $\mathrm{Cu}(110)$ surface $(\mathrm{Cu}$, green; $\mathrm{O}$, red; $\mathrm{C}$, gray, and $\mathrm{H}$, dark gray). The bridge configuration is shown, where the OCO group forms a bridge between the $\mathrm{Cu}$ surface atoms $\mathrm{Cu}^{15}$ and $\mathrm{Cu}^{19}$. By displacing the molecule along the [110] direction with half of the distance $\mathrm{Cu}^{15}-\mathrm{Cu}^{19}$, the top configuration is obtained (where $\mathrm{C}^{21}$ is on top of $\mathrm{Cu}^{19}$ ). There are four $\mathrm{Cu}$ surface atoms, three of them (Nos.15, 17, and 19) are shown in the sideview figures. The fourth one, $\mathrm{Cu}^{13}$, is located behind $\mathrm{Cu}^{15}$ in the side view along [001], and behind $\mathrm{Cu}^{17}$ in the side view along [1ํㅣㄹ. In this bridge configuration, each oxygen binds to one $\mathrm{Cu}$ atom (Nos.15 and 19), and the $\mathrm{Cu}$ surface atoms form two groups by symmetry: $\mathrm{Cu}^{13}$ is equivalent to $\mathrm{Cu}^{17}$, and $\mathrm{Cu}^{15}$ to $\mathrm{Cu}^{19}$.

the copper atoms. It is shown that the $\mathrm{O}-\mathrm{Cu}^{1+}$ attractive interaction is very strong, with the $\mathrm{O}-\mathrm{Cu}$ bond length being $1.910 \AA$ for the diformate molecule and $1.958 \AA$ for the formic acid..$^{37,38}$ The reported $\mathrm{Cu}-\mathrm{O}$ bond length is close to our calculated $\mathrm{Cu}-\mathrm{O}$ bond length $(1.994 \AA)$ for the bridge configuration of the formate molecules on the $\mathrm{Cu}(110)$ surface. It is generally accepted that $\mathrm{Cu}-\mathrm{O}$ distances of 1.91 up to $2.0 \AA$ correspond to a strong $\mathrm{Cu}-\mathrm{O}$ interaction. ${ }^{3,39}$ 
TABLE IV. Bond lengths and relative energies for one formate molecule in a $(2 \times 2)$ unit cell (for the numbering of the atoms, we refer to Fig. 1). Interlayer relaxations are given in $\%$ relative to the ideal bulk terminated surface.

\begin{tabular}{|c|c|c|c|c|c|}
\hline & \multicolumn{2}{|c|}{ Position } & & \multicolumn{2}{|c|}{ Position } \\
\hline & Bridge & Top & & Bridge & Top \\
\hline \multicolumn{3}{|c|}{ Bond length $(\AA)$} & \multicolumn{3}{|c|}{ Interlayer relaxations $(\%)$} \\
\hline $\mathrm{C}^{21}-\mathrm{H}^{27}$ & 1.141 & 1.146 & $\mathrm{Cu}^{13}-\mathrm{Cu}^{11}$ & -10.06 & -2.02 \\
\hline $\mathrm{C}^{21}-\mathrm{O}^{23}$ & 1.321 & 1.324 & $\mathrm{Cu}^{15}-\mathrm{Cu}^{11}$ & -0.85 & +0.37 \\
\hline $\mathrm{C}^{21}-\mathrm{O}^{25}$ & 1.321 & 1.324 & $\mathrm{Cu}^{17}-\mathrm{Cu}^{11}$ & -10.06 & -1.95 \\
\hline $\mathrm{O}^{23}-\mathrm{Cu}^{15}$ & 1.994 & $2.441^{\mathrm{a}}$ & $\mathrm{Cu}^{19}-\mathrm{Cu}^{11}$ & -0.84 & +0.32 \\
\hline $\mathrm{O}^{23}-\mathrm{Cu}^{19}$ & & $2.434^{\mathrm{a}}$ & \multicolumn{3}{|c|}{ Clean $\mathrm{Cu}(110)$ surface } \\
\hline $\mathrm{O}^{25}-\mathrm{Cu}^{19}$ & 1.994 & $2.320^{\mathrm{b}}$ & \multicolumn{3}{|c|}{-11.00} \\
\hline $\mathrm{O}^{25}-\mathrm{Cu}^{15}$ & & $2.314^{\mathrm{b}}$ & & & \\
\hline
\end{tabular}

Angle $\left({ }^{\circ}\right)$

Relative total energies (ev)

\begin{tabular}{lllll}
\hline $\mathrm{O}^{23} \mathrm{C}^{21} \mathrm{O}^{25}$ & 128.41 & 125.32 & 0.00 & 0.45 \\
\hline
\end{tabular}

These are equivalent bond lengths. The agreement $\left(\approx 5 \times 10^{-3} \AA\right)$ is satisfactory for our calculations without imposing symmetry.

${ }^{\mathrm{b}}$ These are equivalent bond lengths. The agreement $\left(\approx 5 \times 10^{-3} \AA\right)$ is satisfactory for our calculations without imposing symmetry.

Electronic structure. Obviously, the chemical bonding between the carboxylate group and the copper surface is neither purely ionic (Coulombic) nor covalent. We identify that both interactions play a role in the bonding of the formate molecule with the $\mathrm{Cu}(110)$ surface, and that the stronger covalent interaction favors the adsorption of the formate molecule via the carboxylate group in the bridge position. Detailed information on the bonding characteristics and the electronic structure of the adsorbed formate molecule can be obtained by analyzing the partial local density of states (PLDOS) and the spatial distribution of the wave functions. The energy range of interest for understanding the bonding and/or coupling of formate-Cu surface atoms is the $\mathrm{Cu} d$ bands between -4.5 and $-1.0 \mathrm{eV}$ below the Fermi level. The partial local densities of states corresponding to the low coverage for bridge and top positions are directly compared in Figs. 2(a)-2(d), which show the PLDOS for the O atoms of the adsorbed formate molecule and for two nonequivalent $\mathrm{Cu}$ surface atoms $\left(\mathrm{Cu}^{15}\right.$ and $\left.\mathrm{Cu}^{13}\right)$ integrated over the augmentation sphere.

The hybridization of the molecular orbitals with the $d$ bands of the copper atoms clearly show up in the plots of the PLDOS. For the bridge configuration, each $\mathrm{O}$ atom binds to one $\mathrm{Cu}$ atom, and the behavior of the PLDOS for $\mathrm{O}$ and $\mathrm{Cu}$ atoms is easily understood in terms of the Anderson-Newns model, ${ }^{40}$ which describes the interaction of a localized atomic orbital with the extended metallic states. In the case of $\mathrm{Cu}$ with a completely occupied $d$ band, the model predicts that both bonding and antibonding states are formed, analog to the bonding and antibonding molecular orbitals which are formed by the orbitals of two interacting atoms (see Fig. 3).

It turns out that this simple picture is qualitatively valid not only in the case of atomic adsorption but generally also in the case of the adsorption of molecules that use anchoring groups to bind the metal surfaces. ${ }^{40,41}$ The features discussed above can be identified in the PLDOS at the $\mathrm{O}$ atoms: There is a set of orbitals at lower energies (from -4 to $-2.5 \mathrm{eV}$ ) which are the bonding combinations, while the ones with higher energies (from -2 to $-0.8 \mathrm{eV}$ ) are the antibonding combinations. At the $\mathrm{Cu}^{15}$ atoms (binding to the $\mathrm{O}$ atoms), the antibonding combinations show up in two peaks above the undistorted $\mathrm{Cu} d$ band, which are not present at the $\mathrm{Cu}^{13}$ atoms (not binding to $\mathrm{O}$ atoms). Figure 4 shows the spatial distribution of four characteristic wave functions, two for each range [the corresponding PLDOS peaks can be seen in Fig. 2(a)]. They clearly show the expected binding behavior. The PLDOS analysis shows that, in general, for the bridge configuration the height of the $p$ peaks located at the $\mathrm{O}$ atom and the $d$ band peaks of $\mathrm{Cu}$ surface atoms are smaller compared to those for the top configuration. This indicates that for the bridge configuration much more charge is transferred from the region located near the atoms [the augmentation sphere (see Sec. III) where the integration for the PLDOS is done] to the interstitial region. Also, for the bridge configuration, the total density of states shows a downshift of the occupied energy levels compared to those for the top configuration [Fig. 2(e)], which leads to a lower total electron energy. In the bridge configuration, the $\mathrm{Cu}-\mathrm{O}$ bond length is only slightly larger than the sum of the covalent radii of the $\mathrm{Cu}$ and $\mathrm{O}$ atoms (4.7\%). Moreover, the wave-function analysis shows the interface orbitals with a clear-cut bonding and antibonding character (see Fig. 4). Due to the effective molecule-metal hybridization of the formate highest occupied molecular orbitals, the adsorption process may indeed be described in terms of chemisorption, with the formation of the true chemical bonds at the formate-copper interface with mixed molecular and metallic character.

In the top configuration, the $\mathrm{Cu}-\mathrm{O}$ bond length is much larger than the sum of the covalent radii of the $\mathrm{Cu}$ and $\mathrm{O}$ 

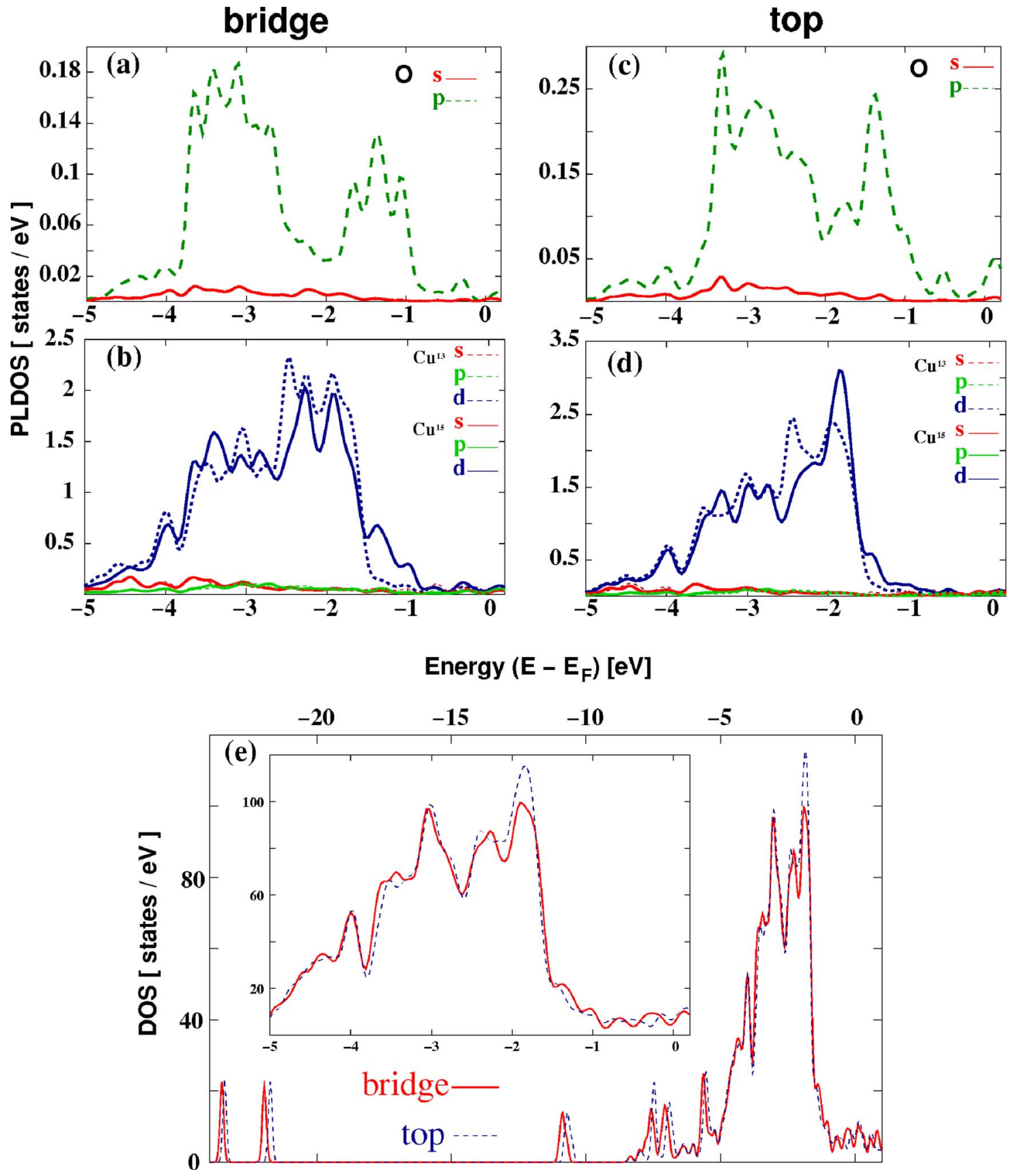

FIG. 2. (Color online) (a)-(d): Comparison of the partial local density of states (PLDOS) as a function of energy for the two adsorption geometries of formate on $\mathrm{Cu}(110)$; left panels, bridge position; right panels, top position. For each adsorption geometry, the PLDOS integrated over the augmentation sphere (see Sec. III) around $\mathrm{O}\left[(\mathrm{a})\right.$ and (c)] and around two nonequivalent $\mathrm{Cu}$-surface atoms $\left[\mathrm{Cu}{ }^{15}\right.$ full lines and $\mathrm{Cu}^{13}$ broken lines in (b) and (d)] decomposed into angular momentum contributions ( $s$, red; $p$, green; and $d$, blue) are shown. The $\mathrm{Cu}-\mathrm{O}$ bonding states are found in the range of the $\mathrm{Cu} d$ band, located between -4.5 and $-1.0 \mathrm{eV}$ below the Fermi energy $\left(E_{F}\right.$ is set to zero in the plots). The states between $-1.8 \mathrm{eV}$ and $E_{F}$ have a metal-molecule antibonding character, whereas metal-molecule bonding states appear in the lower edge of the $\mathrm{Cu} d$ bands (from -4.5 to $-1.8 \mathrm{eV}$ ). Characteristic of the bridge position (b) are the two peaks around -1.0 and $-1.6 \mathrm{eV}$ at the $\mathrm{Cu}^{15}$ site $\left(\mathrm{Cu}^{15}\right.$ binds to $\left.\mathrm{O}\right)$ which are not present for the nonbinding $\mathrm{Cu}^{13}$ surface atoms. In the case of the top position (d), the weight of the two peaks (appearing for $\mathrm{Cu}^{15}$, which is the one nearer to the $\mathrm{O}$ atom in this configuration) is significantly lower. (e) Comparison of the total local density of states (DOS) as a function of energy for the two adsorption geometries (bridge, red; top, blue) of formate on $\mathrm{Cu}(110)$.

atoms (22.1\%-27.9\%). The wave-function analysis shows interface orbitals with no clear-cut bonding and antibonding character (a connected isosurface between the $\mathrm{Cu}$ and $\mathrm{O}$ atoms is achieved only when choosing a density parameter at least 2 orders of magnitude smaller compared to the bridge configuration). Therefore we conclude that the $\mathrm{Cu}-\mathrm{O}$ bond is unlikely to be strongly covalent and the main driving force for the binding is the Coulomb interaction, as also stated by 


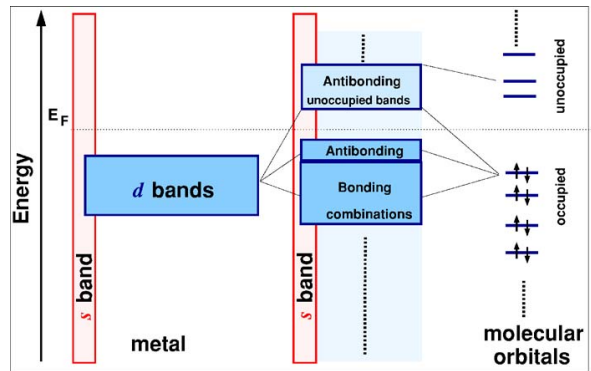

FIG. 3. (Color online) Schematic view of the hybridization of formate molecular orbitals with $\mathrm{Cu} d$ band wavefunctions. On the $\mathrm{O}$ atoms of the formate molecules, the hybridization leads to a splitting in to two subbands. On the $\mathrm{Cu}$ atoms, the antibonding combinations have energies slightly above the original $\mathrm{Cu} d$ band.

Preuss et $a .^{42}$ The molecule-metal hybridization of the formate highest occupied molecular orbitals and the $d$ bands of the copper surface is not as efficient as for the bridge configuration. Another proof for the Coulomb contribution to the binding of the formate molecule with the copper surface are total charge-difference plots for the two adsorption geometries (bridge and top positions). The spatially resolved charge difference, $\Delta \rho$, is calculated accordingly to the formula

$$
\Delta \rho(r)=\rho_{\mathrm{HCOO}-\mathrm{Cu}(110)}(r)-\rho_{\mathrm{Cu}(110)}(r)-\rho_{\mathrm{HCOO}}(r),
$$

where $\rho_{\mathrm{HCOO}-\mathrm{Cu}(110)}$ is the charge density of the relaxed formate- $\mathrm{Cu}(110)$ system, $\rho_{\mathrm{Cu}(110)}$ the charge density of the clean $\mathrm{Cu}(110)$ surface (without the molecular layer), and $\rho_{\mathrm{HCOO}}$ the charge density of the free formate molecule placed in the respective adsorption configuration (bridge or top). Figure 5 shows the regions of electron accumulation and/or depletion displayed in red and/or blue for the isosurface value of 0.008 e/a.u. ${ }^{3}$. For both adsorption geometries, we identify an electron accumulation around the $\mathrm{O}$ atoms and a depletion of electrons from the copper surface atoms.
To summarize, from the wave-function analysis, the PLDOS, and the total charge-difference plots, we conclude that the adsorption of the formate molecule in the bridge configuration has strong covalent $\mathrm{Cu}-\mathrm{O}$ bonds due to the hybridization of the highest occupied molecular orbitals of the formate molecule with copper $d$ bands. On the contrary, for the adsorption in top configuration, the Coulomb interaction plays the decisive role and the hybridization of the molecular levels with the $d$ bands of the copper surface is less efficient.

\section{High formate coverage on $\mathrm{Cu}(110)$ surface}

For high formate coverage on the clean $\mathrm{Cu}(110)$ surface, where two molecules are present in a $(2 \times 2)$ unit cell, three different configurations are tested: one with both molecules in the bridge position (bridge-bridge configuration, see Fig. 6), another one with both molecules in the top position (toptop configuration), and a third configuration with one molecule in the bridge position and the other one in the top position (bridge-top configuration).

We present the details of the formate arrangements for high coverage in two tables: Table $\mathrm{V}$ shows the intramolecular bond lengths and bond angles and the atomic distances in the $\mathrm{Cu}$ surface, and Table VI shows the $\mathrm{Cu}-\mathrm{O}$ bond lengths and relative energies. For the numbering of the atoms we refer to Fig. 6.

Atomic structure and energetics. The most stable configuration for high coverage is the one with both molecules in the bridge position. In Table VI the energies for the other optimized configurations are given relative to the energy of the bridge configuration. A positive energy indicates that the specific structure is less stable. The geometries of the formate molecules are quite similar in all configurations with two molecules per unit cell. The main differences appear in the $\mathrm{Cu}-\mathrm{O}$ bond lengths and the relaxations of the copper surface atoms. As for formate adsorption in the bridge position for low coverage (with one molecule per unit cell), the oxygen-bound copper atoms relax outward relative to the clean $\mathrm{Cu}(110)$ surface. With two molecules per unit cell, both

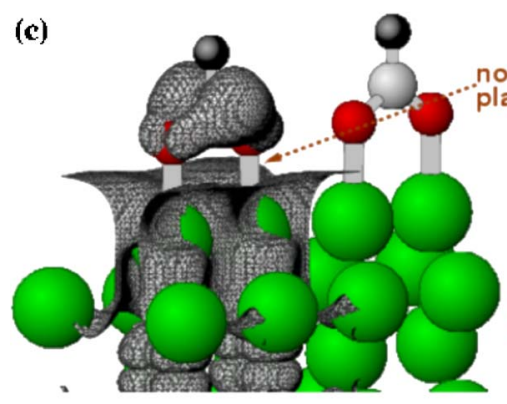

(a)

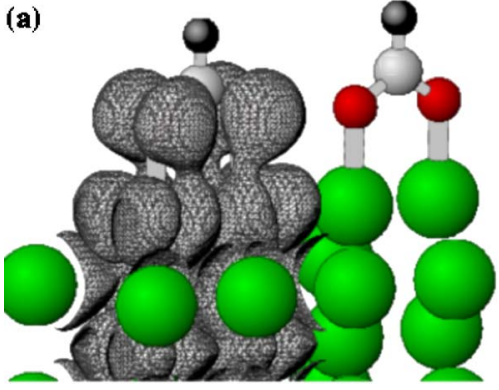

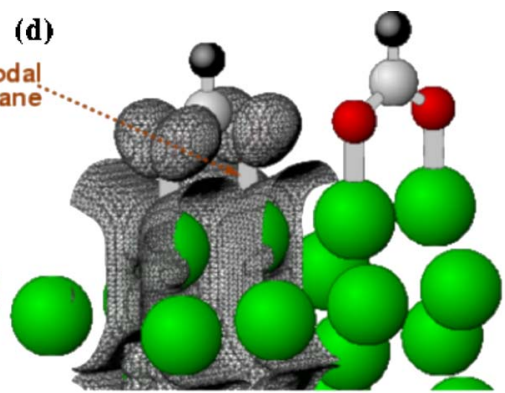

(b)

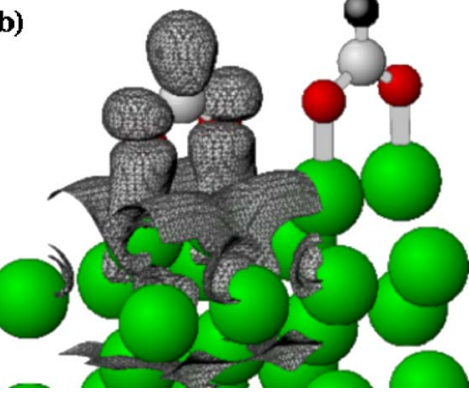

FIG. 4. (Color online) Isodensity surfaces for molecule-metal hybrid wave functions of formate adsorbed on $\mathrm{Cu}(110)$ in the bridge configuration ( $\mathrm{Cu}$, green; $\mathrm{O}$, red; $\mathrm{C}$, gray; and $\mathrm{H}$, dark gray). (a) and (b) show bonding combinations with the eigenvalues $\varepsilon=-2.7$ and $\varepsilon=-3.6 \mathrm{eV}$. (c) and (d) show antibonding combinations with the eigenvalues $\varepsilon=-1.0$ and $\varepsilon=-1.6 \mathrm{eV}$. 

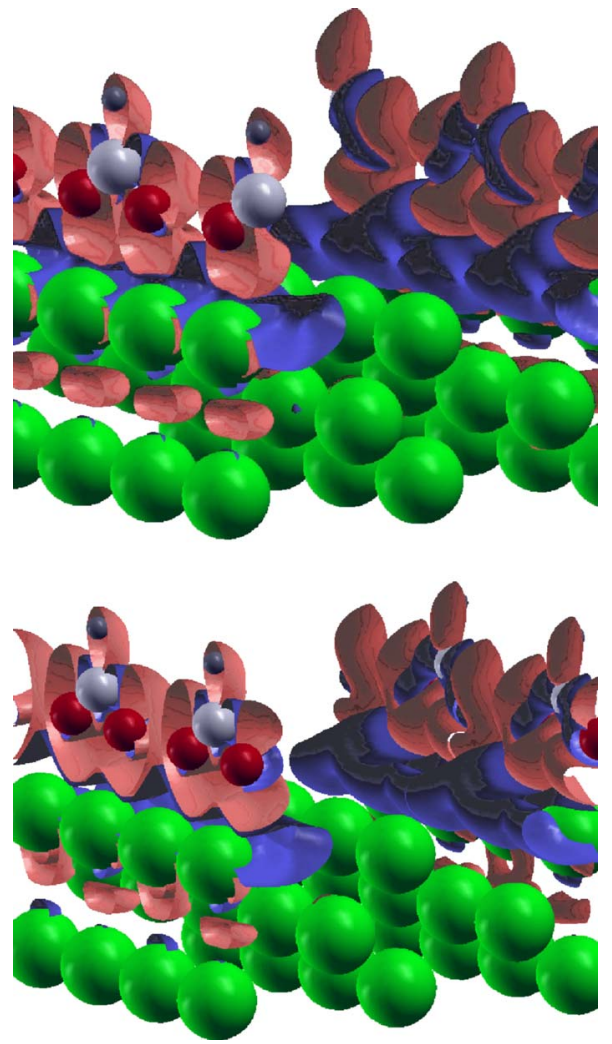

FIG. 5. (Color online) Total charge-difference plots for the bridge and top configurations of formate adsorbed on $\mathrm{Cu}(110)$ compared to the isolated sytems $(\mathrm{Cu}$, green; $\mathrm{O}$, red; $\mathrm{C}$, gray; and $\mathrm{H}$, dark gray). Regions of electron accumulation and/or depletion are displayed in red (light gray) and/or blue (dark gray) for an isosurface of $0.008 \mathrm{e} / \mathrm{a} . u{ }^{3}$. There is an accumulation of electrons around the oxygen atoms due to a depletion of electrons from the copper surface atoms. From the smaller volume included inside the equicharge surface, we can conclude that for the bridge configuration less charge is transferred from the surface to the oxygen atoms.

in bridge positions, all $\mathrm{Cu}$ atoms are affected and the outward relaxations are larger than for low coverage (see Tables IV and $\mathrm{V}$ ). As discussed above, the small $\mathrm{O}-\mathrm{Cu}$ bond length when both molecules are in the bridge position is indicative of a strong attractive $\mathrm{O}-\mathrm{Cu}$ interaction.,37-39 In the most stable structure, the $\mathrm{O}-\mathrm{Cu}$ bonds are all equal. Also the outward relaxations of all copper atoms of the first layer are the same. Due to the $\mathrm{O}-\mathrm{Cu}$ bonds, the inward relaxation of the clean $\mathrm{Cu}(110)$ surface is overcompensated.

When one of the molecules is placed in the top position (mixed configuration), the energy increases by $0.52 \mathrm{eV}$, a little more than the $0.45 \mathrm{eV}$ found for low coverage. As for low coverage, the increase of energy is mostly due to the different $\mathrm{O}-\mathrm{Cu}$ bonds. A small contribution comes from different relaxations of the copper surface atoms. The rest of the difference can be attributed to different interactions between the formate molecules. The same is true when both molecules are in the top position. The increase of energy $(1.03 \mathrm{eV})$ is larger than $2 \times 0.45 \mathrm{eV}$.

The stability of the phases with high or low formate coverage on $\mathrm{Cu}(110)$ due to repulsion or attraction between the adsorbed molecules can be estimated by comparing the en-
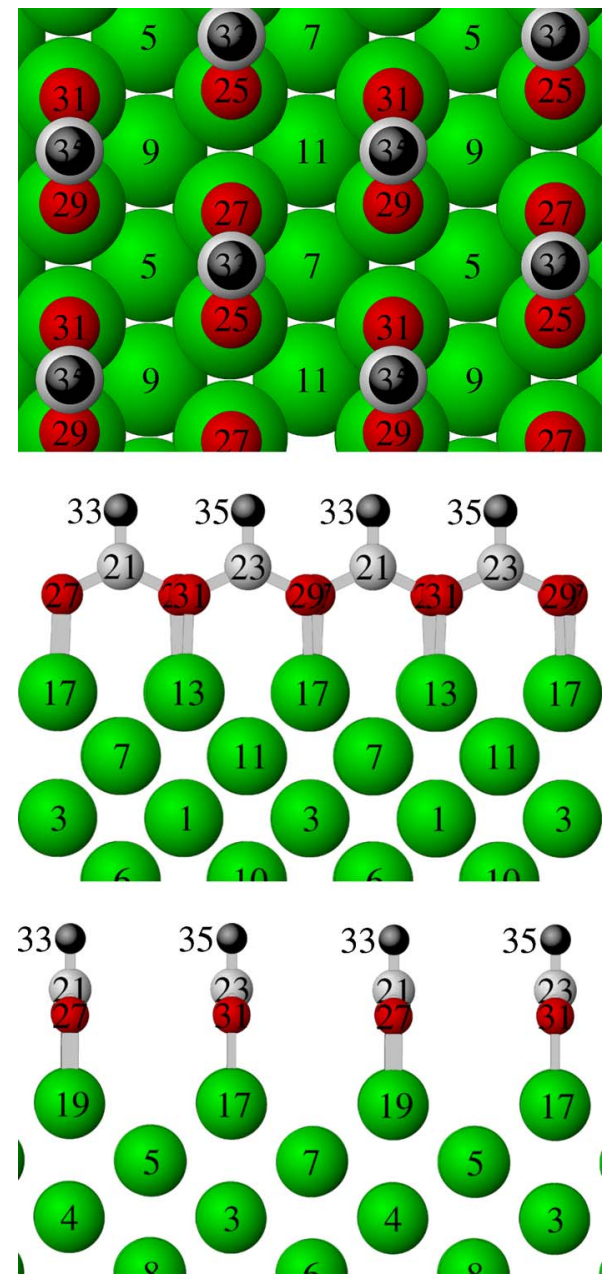

FIG. 6. (Color online) Adsorption geometry of two formate molecules in a $(2 \times 2)$ unit cell on a clean $\mathrm{Cu}(110)$ surface $(\mathrm{Cu}$, green; $\mathrm{O}$, red; $\mathrm{C}$, gray; and $\mathrm{H}$, dark gray). Shown is the bridge-bridge configuration $\left(\mathrm{C}^{21}\right.$ on bridge between $\mathrm{Cu}^{15}-\mathrm{Cu}^{19}$ and $\mathrm{C}^{23}$ on bridge between $\mathrm{Cu}^{13}-\mathrm{Cu}^{17}$ ). By displacing both molecules along the $[1 \overline{1} 0]$ direction with half of the distance $\mathrm{Cu}^{15}-\mathrm{Cu}^{19}$ and $\mathrm{Cu}^{13}-\mathrm{Cu}^{17}$, the top-top configuration is obtained $\left(\mathrm{C}^{21}\right.$ on top of $\mathrm{Cu}^{19}$ and $\mathrm{C}^{23}$ on top of $\left.\mathrm{Cu}^{13}\right)$. By displacing only one molecule along the $[1 \overline{10}]$ direction with half of the distance $\mathrm{Cu}^{13}-\mathrm{Cu}^{17}$, the bridge-top configuration is obtained $\left(\mathrm{C}^{21}\right.$ on bridge between $\mathrm{Cu}^{15}-\mathrm{Cu}^{19}$ and $\mathrm{C}^{23}$ on top of $\left.\mathrm{Cu}^{13}\right)$.

ergies of a given area of the $\mathrm{Cu}$ surface for two different arrangements of the formate molecules: (i) the formate is spread out on the copper surface with low coverage [i.e., one molecule per $(2 \times 2)$ unit cell] and (ii) the formate molecules are present on only half of the surface area with double (high) coverage [i.e., two molecules per $(2 \times 2)$ unit cell] and half of the $\mathrm{Cu}$ surface area is free of formate. The two situations yield the following energy difference per formate molecule:

$$
0.25\left[2 E_{\mathrm{Cu}(110)}^{1 \text { formate }}-\left(E_{\mathrm{Cu}(110)}+E_{\mathrm{Cu}(110)}^{2} \text { formate }\right)\right]=\Delta E_{1},
$$

where $E_{\mathrm{Cu}(110)}^{1 \text { formate }}$ and $E_{\mathrm{Cu}(110)}^{\text {fformate }}$ are the slab energies of the (2 $\times 2) \mathrm{Cu}(110)$ unit cell with one and two molecules, respec- 
TABLE V. Two formate molecules in a $(2 \times 2)$ unit cell on the clean $\mathrm{Cu}(110)$ surface. Bond lengths of the molecules are in angstroms and relaxations of the $\mathrm{Cu}$ atoms of the first layer are expressed in \% relative to the ideal interlayer distance where the $\mathrm{Cu}$ atoms have the bulk terminated positions.

\begin{tabular}{lccc}
\hline \hline & \multicolumn{3}{c}{ Position } \\
\cline { 2 - 4 } & \multicolumn{3}{c}{ Bond length $(\AA)$} \\
& 1.142 & 1.143 & 1.141 \\
$\mathrm{C}^{21}-\mathrm{H}^{33}$ & 1.142 & 1.143 & 1.145 \\
$\mathrm{C}^{23}-\mathrm{H}^{35}$ & 1.320 & 1.323 & 1.322 \\
$\mathrm{C}^{21}-\mathrm{O}^{25}$ & 1.320 & 1.323 & 1.321 \\
$\mathrm{C}^{21}-\mathrm{O}^{27}$ & 1.320 & 1.323 & 1.323 \\
$\mathrm{C}^{23}-\mathrm{O}^{29}$ & 1.320 & 1.323 & 1.326 \\
$\mathrm{C}^{23}-\mathrm{O}^{31}$ & \multicolumn{3}{c}{ Angle $\left(^{\circ}\right)$} \\
& 129.10 & 126.35 & 128.51 \\
$\mathrm{O}^{25} \mathrm{C}^{21} \mathrm{O}^{27}$ & 128.69 & 126.35 & 126.12 \\
$\mathrm{O}^{29} \mathrm{C}^{23} \mathrm{O}^{31}$ & Interlayer & \\
& & & \\
$\mathrm{Cu}^{13}-\mathrm{Cu}^{11}$ & +1.17 & -0.54 & -0.04 \\
$\mathrm{Cu}^{15}-\mathrm{Cu}^{11}$ & +1.17 & -1.34 & -0.72 \\
$\mathrm{Cu}^{17}-\mathrm{Cu}^{11}$ & +1.17 & -1.34 & -1.54 \\
$\mathrm{Cu}^{19}-\mathrm{Cu}^{11}$ & +1.17 & -0.54 & -0.70 \\
$\mathrm{Clean} \mathrm{Cu}^{2110)}$ surface & & -11.00 & \\
\hline \hline
\end{tabular}

tively (with the molecules in bridge positions), and $E_{\mathrm{Cu}(110)}$ represents the energy of the clean $\mathrm{Cu}(110)$ surface. An extra factor of 2 enters because there are two identical surfaces in the slab. If $\Delta E_{1}>0$, the interaction between the molecules is attractive, and it is repulsive if $\Delta E_{1}<0$. Our results for the total energies of the different $\mathrm{Cu}(110)$ surfaces (with and without formate) yield a small positive energy difference, $\Delta E_{1}=+0.1197 \mathrm{eV}$ per molecule. This would mean that an attractive interaction of the adsorbed formate molecules exists, in contradiction to the earlier experimental suggestions ${ }^{13}$ which postulate a repulsive interaction between formate molecules on the $\mathrm{Cu}(110)$ surface from the fact that the highcoverage configuration is not achievable by long exposure of the $\mathrm{Cu}(110)$ surface with formic acid in the gas phase. However, while our calculations test the equilibrium configurations of formate molecules on the surface at $T=0$, the experiments draw the conclusions from the kinetics of the adsorption reaction. The ultimate test is to calculate the barrier for adsorption of a second formate molecule in the $(2$ $\times 2$ ) unit cell. We have done preliminary calculations (without allowing any relaxations) with the formic acid molecule approaching the copper surface in a $(2 \times 2)$ unit cell which contains an adsorbed formate molecule. We estimate an energetic barrier of about $2 \mathrm{eV}$. A complete investigation requires the relaxation of all the atoms in the unit cell, but this is a very demanding calculation and has to be left for future investigations.
TABLE VI. $\mathrm{Cu}-\mathrm{O}$ bond lengths and relative energies for two formate molecules in a $(2 \times 2)$ unit cell on the clean $\mathrm{Cu}(110)$ surface (oxygen-copper bond lengths are given in $\AA$ ).

\begin{tabular}{|c|c|c|c|c|c|c|}
\hline \multirow{2}{*}{$\begin{array}{l}\text { Molecule } \\
\text { position }\end{array}$} & \multirow[b]{2}{*}{ Atom } & \multicolumn{4}{|c|}{ Bond length $(\AA)$} & \multirow{2}{*}{$\begin{array}{c}\text { Energy } \\
(\mathrm{eV})\end{array}$} \\
\hline & & $\mathrm{Cu}^{13}$ & $\mathrm{Cu}^{15}$ & $\mathrm{Cu}^{17}$ & $\mathrm{Cu}^{19}$ & \\
\hline \multirow{4}{*}{$\begin{array}{l}\text { Bridge- } \\
\text { bridge }\end{array}$} & $\mathrm{O}^{25}$ & & 1.998 & & & \\
\hline & $\mathrm{O}^{27}$ & & & & 1.998 & \\
\hline & $\mathrm{O}^{29}$ & & & 1.998 & & 0.0000 \\
\hline & $\mathrm{O}^{31}$ & 1.998 & & & & \\
\hline \multirow{4}{*}{$\begin{array}{l}\text { One bridge } \\
\text { and one top }\end{array}$} & $\mathrm{O}^{25}$ & & 1.993 & & & \\
\hline & $\mathrm{O}^{27}$ & & & & 1.989 & \\
\hline & $\mathrm{O}^{29}$ & 2.334 & & 2.461 & & 0.5229 \\
\hline & $\mathrm{O}^{31}$ & 2.340 & & 2.475 & & \\
\hline \multirow{4}{*}{$\begin{array}{l}\text { Top- } \\
\text { top }\end{array}$} & $\mathrm{O}^{25}$ & & 2.456 & & 2.327 & \\
\hline & $\mathrm{O}^{27}$ & & 2.450 & & 2.334 & \\
\hline & $\mathrm{O}^{29}$ & 2.334 & & 2.448 & & 1.0257 \\
\hline & $\mathrm{O}^{31}$ & 2.326 & & 2.456 & & \\
\hline
\end{tabular}

\section{High formate coverage on oxygen-precovered $\mathrm{Cu}(110)$ surface}

In the case of the oxygen-precovered $\mathrm{Cu}(110)$ surface with two formate molecules in the $(2 \times 2)$ unit cell, the oxygen atom of $0.25 \mathrm{ML}$ has been placed in a hollow site (between four copper atoms of the first layer and on top of a copper atom of the second layer), as is suggested by previous calculations. ${ }^{35}$ In this case, four configurations are possible. One contains both molecules in the bridge position and another one has both molecules in the top position. For these configurations, all hollow sites of the copper surface in the unit cell are equivalent (Fig. 7). In the case when one molecule is in the bridge position and the other one is in the top position, there are two nonequivalent positions of the oxygen atom $(0.25 \mathrm{ML})$ relative to the copper surface and formate molecules (see Fig. 7).

We give the details of the arrangement of the formate molecules on the oxygen-precovered $\mathrm{Cu}(110)$ surface in three different tables: Table VII shows the intramolecular bond lengths, bond angles, and interlayer relaxations of the $\mathrm{Cu}(110)$ surface; Table VIII the bond lengths of the oxygen atoms of the formate molecules with the copper surface atoms and the energies of the different formate adsorption geometries; and Table IX the bond lengths of the extra oxygen atoms with the $\mathrm{Cu}$ surface atoms. For the numbering of the atoms we refer to Fig. 7.

Atomic structure and energetics. In the case of the oxygen-precovered $\mathrm{Cu}(110)$ surface, the most stable configuration also turns out to be the one with both molecules occupying bridge positions. It is characteristic for all configurations that due to the $\mathrm{O}-\mathrm{Cu}$ bonds the first copper layer relaxes outward above the ideal bulk terminated positions and the first interlayer distance increases. Again the inward 

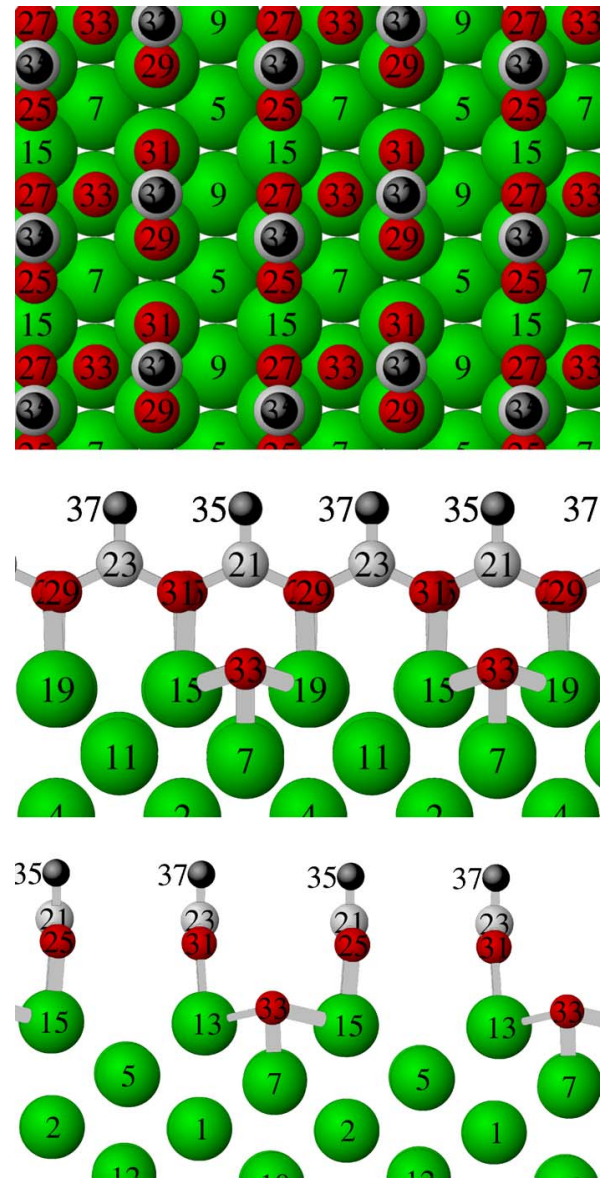

FIG. 7. (Color online) Adsorption geometry of two formate molecules in a $(2 \times 2)$ unit cell on a $0.25 \mathrm{ML}$ oxygen-precovered $\mathrm{Cu}(110)$ surface $(\mathrm{Cu}$, green; $\mathrm{O}$, red; $\mathrm{C}$, gray; and $\mathrm{H}$, dark gray). Shown is the bridge-bridge configuration $\left(\mathrm{C}^{21}\right.$ on bridge between $\mathrm{Cu}^{15}-\mathrm{Cu}^{19}$ and $\mathrm{C}^{23}$ on bridge between $\left.\mathrm{Cu}^{13}-\mathrm{Cu}^{17}\right)$. By displacing both molecules along the $[1 \overline{1} 0]$ direction with half of the distance $\mathrm{Cu}^{15}-\mathrm{Cu}^{19}$ and $\mathrm{Cu}^{13}-\mathrm{Cu}^{17}$, the top-top configuration is obtained $\left(\mathrm{C}^{21}\right.$ on top of $\mathrm{Cu}^{19}$ and $\mathrm{C}^{23}$ on top of $\left.\mathrm{Cu}^{13}\right)$. For both bridge-bridge and top-top configurations, the $0.25 \mathrm{ML}$ oxygen $\left(\mathrm{O}^{33}\right)$ atom is situated on top of $\mathrm{Cu}^{7}$. By displacing only one molecule along the $[1 \overline{1} 0]$ direction with half of the distance $\mathrm{Cu}^{15}-\mathrm{Cu}^{19}$, the bridge-top configurations are obtained $\left(\mathrm{C}^{23}\right.$ on bridge between $\mathrm{Cu}^{13}-\mathrm{Cu}^{17}$ and $\mathrm{C}^{21}$ on top of $\left.\mathrm{Cu}^{19}\right)$. For one bridge-top configuration, the $0.25 \mathrm{ML}$ oxygen $\left(\mathrm{O}^{33}\right)$ atom is situated on top of $\mathrm{Cu}^{7}$ and for the other on top of $\mathrm{Cu}^{11}$.

relaxation for the clean $\mathrm{Cu}(110)$ surface is overcompensated. The extra oxygen atom (the remaining $0.25 \mathrm{ML}$ after water release) is only slightly displaced from the hollow site position. For all configurations, the $\mathrm{Cu}-\mathrm{O}^{33}$ bond length $\left(\mathrm{Cu}^{7}-\mathrm{O}^{33}\right.$ and $\left.\mathrm{Cu}^{11}-\mathrm{O}^{33}\right)$ relative to the second-layer atom is practically the same. The bond length of the lone oxygen atom with copper atoms of the second layer is shorter than the one formed by the oxygen of the molecules with the copper atoms of the first layer (see Tables VII-IX). In Table VIII the energy of the most stable configuration (both formate molecules in bridge positions) is taken as reference. The positive energies indicate the reduced stability of the other configurations.
TABLE VII. Intramolecular bond lengths $(\AA)$ and interlayer relaxations for two formate molecules in a $(2 \times 2)$ unit cell on the oxygen-precovered $\mathrm{Cu}(110)$ surface. The relaxations of the copper atoms of the first layer are expressed in \% relative to the ideal interlayer distance where the copper atoms have the bulk terminated positions.

\begin{tabular}{|c|c|c|c|c|}
\hline & \multicolumn{4}{|c|}{ Position } \\
\hline & 2 bridge & 2 top & $\begin{array}{l}\text { Bridge-top } \\
\left(\mathrm{O}^{33}-\mathrm{C}^{7}\right)\end{array}$ & $\begin{array}{c}\text { Bridge-top } \\
\left(\mathrm{O}^{33}-\mathrm{C}^{11}\right)\end{array}$ \\
\hline \multicolumn{5}{|c|}{ Bond length $(\AA)$} \\
\hline $\mathrm{C}^{21}-\mathrm{H}^{35}$ & 1.139 & 1.142 & 1.153 & 1.150 \\
\hline $\mathrm{C}^{23}-\mathrm{H}^{37}$ & 1.142 & 1.140 & 1.147 & 1.145 \\
\hline $\mathrm{C}^{21}-\mathrm{O}^{25}$ & 1.321 & 1.314 & 1.332 & 1.313 \\
\hline $\mathrm{C}^{21}-\mathrm{O}^{27}$ & 1.321 & 1.331 & 1.315 & 1.328 \\
\hline $\mathrm{C}^{23}-\mathrm{O}^{29}$ & 1.318 & 1.331 & 1.323 & 1.319 \\
\hline $\mathrm{C}^{23}-\mathrm{O}^{31}$ & 1.317 & 1.333 & 1.320 & 1.313 \\
\hline \multicolumn{5}{|c|}{ Angle $\left(^{\circ}\right)$} \\
\hline $\mathrm{O}^{25} \mathrm{C}^{21} \mathrm{O}^{27}$ & 129.75 & 126.38 & 125.30 & 125.58 \\
\hline $\mathrm{O}^{29} \mathrm{C}^{23} \mathrm{O}^{31}$ & 128.24 & 126.39 & 128.68 & 127.44 \\
\hline \multicolumn{5}{|c|}{ Interlayer relaxations $(\%)$} \\
\hline $\mathrm{Cu}^{13}-\mathrm{Cu}^{11}$ & +8.28 & +8.16 & +11.27 & +5.66 \\
\hline $\mathrm{Cu}^{15}-\mathrm{Cu}^{11}$ & +8.27 & +7.22 & +11.69 & +5.63 \\
\hline $\mathrm{Cu}^{17}-\mathrm{Cu}^{11}$ & +8.28 & +7.22 & +11.62 & +5.81 \\
\hline $\mathrm{Cu}^{19}-\mathrm{Cu}^{11}$ & +8.27 & +8.13 & +13.81 & +6.85 \\
\hline \multicolumn{5}{|c|}{ Clean $\mathrm{Cu}(110)$ surface -11.00} \\
\hline
\end{tabular}

The calculated bond lengths of the extra oxygen atom $\left(\mathrm{Cu}^{7 / 11}-\mathrm{O}^{33}\right)$ are in good agreement with experimental results and theoretical calculations of the oxygen-precovered $\mathrm{Cu}(110)$ surface. ${ }^{35,38,43-47}$ The $\mathrm{O}^{33}$ position is slightly above the first layer of copper atoms (see Fig. 7). Similar to our results, Liem et al. ${ }^{35}$ reported that at low coverage of oxygen on the $\mathrm{Cu}(110)$ surface the most favorable adsorption site of the additional oxygen atom is not the hollow site (highsymmetry fourfold coordination). Instead, the equilibrium position corresponds to a pseudo-threefold-coordinated adsorption site. The oxygen is in a midpoint between a hollow site and two copper nearest-neighbor atoms along the [1 10$]$ direction. This is explained by the closer coordination (shorter bond lengths) of the oxygen to the copper atoms for the pseudo-threefold-coordinated adsorption site.

We find that for the most stable configuration of formate adsorption on the $0.25 \mathrm{ML}$ oxygen-precovered $\mathrm{Cu}(110)$ surface (with both molecules in the bridge position), the additional oxygen atom follows the same trend: it is displaced from the hollow site and likes to coordinate closer to three $\mathrm{Cu}$-surface atoms (see Table IX); the $\mathrm{O}^{33}$ forms slightly shorter bonds to $\mathrm{Cu}^{13}$ and $\mathrm{Cu}^{17}$ and longer ones with $\mathrm{Cu}^{15}$ and $\mathrm{Cu}^{19}$. The direction of relaxation is the same as the one found by Liem et al. ${ }^{35}$ (see Fig. 8).

For the oxygen precovered $\mathrm{Cu}(110)$ surface, the energy difference between the most stable configuration (with both 
TABLE VIII. $\mathrm{Cu}-\mathrm{O}$ bond lengths $(\AA)$ and energies (in eV) for two formate molecules in a $(2 \times 2)$ unit cell on the oxygenprecovered $\mathrm{Cu}(110)$ surface.

\begin{tabular}{|c|c|c|c|c|c|c|}
\hline \multirow{2}{*}{$\begin{array}{l}\text { Molecule } \\
\text { position }\end{array}$} & \multirow[b]{2}{*}{ Atom } & \multicolumn{4}{|c|}{ Bond length $(\AA)$} & \multirow{2}{*}{$\begin{array}{c}\text { Energy } \\
(\mathrm{eV})\end{array}$} \\
\hline & & $\mathrm{Cu}^{13}$ & $\mathrm{Cu}^{15}$ & $\mathrm{Cu}^{17}$ & $\mathrm{Cu}^{19}$ & \\
\hline \multirow{4}{*}{$\begin{array}{l}\text { Bridge- } \\
\text { brige }\end{array}$} & $\mathrm{O}^{25}$ & & 1.993 & & & \\
\hline & $\mathrm{O}^{27}$ & & & & 1.993 & \\
\hline & $\mathrm{O}^{29}$ & & & 1.989 & & 0.0000 \\
\hline & $\mathrm{O}^{31}$ & 1.988 & & & & \\
\hline \multirow{4}{*}{$\begin{array}{l}\text { Top- } \\
\text { top }\end{array}$} & $\mathrm{O}^{25}$ & & 2.494 & & 2.377 & \\
\hline & $\mathrm{O}^{27}$ & & 2.381 & & 2.235 & \\
\hline & $\mathrm{O}^{29}$ & 2.235 & & 2.382 & & 0.8471 \\
\hline & $\mathrm{O}^{31}$ & 2.377 & & 2.494 & & \\
\hline \multirow{4}{*}{$\begin{array}{l}\text { One bridge } \\
\text { and one top } \\
\left(\mathrm{O}^{33}-\mathrm{C}^{7}\right)\end{array}$} & $\mathrm{O}^{25}$ & & 2.493 & & 2.347 & \\
\hline & $\mathrm{O}^{27}$ & & 2.428 & & 2.301 & \\
\hline & $\mathrm{O}^{29}$ & & & 1.987 & & 0.5417 \\
\hline & $\mathrm{O}^{31}$ & 1.986 & & & & \\
\hline \multirow{4}{*}{$\begin{array}{l}\text { One bridge } \\
\text { and one top } \\
\left(\mathrm{O}^{33}-\mathrm{C}^{11}\right)\end{array}$} & $\mathrm{O}^{25}$ & & 2.449 & & 2.281 & \\
\hline & $\mathrm{O}^{27}$ & & 2.566 & & & \\
\hline & $\mathrm{O}^{29}$ & & & 2.003 & & 0.76206 \\
\hline & $\mathrm{O}^{31}$ & 1.998 & & & & \\
\hline
\end{tabular}

molecules in the bridge position) and the least stable one (with both molecules in the top position) is $0.85 \mathrm{eV}$, which is less than the corresponding energy difference for the clean surface $(1.03 \mathrm{eV})$. The presence of additional oxygen apparently influences the energy difference between different for-

TABLE IX. Bond lengths $(\AA)$ of the additional oxygen $\left(\mathrm{O}^{33}\right)$ for two formate molecules in a $(2 \times 2)$ unit cell on the oxygenprecovered $\mathrm{Cu}(110)$ surface.

\begin{tabular}{|c|c|c|c|c|c|c|}
\hline \multirow{2}{*}{$\begin{array}{l}\text { Molecule } \\
\text { position }\end{array}$} & \multicolumn{6}{|c|}{$\mathrm{Cu}-\mathrm{O}^{33}$ bond length $(\AA)$} \\
\hline & $\mathrm{Cu}^{7}$ & $\mathrm{Cu}^{11}$ & $\mathrm{Cu}^{13}$ & $\mathrm{Cu}^{15}$ & $\mathrm{Cu}^{17}$ & $\mathrm{Cu}^{19}$ \\
\hline Bridge-bridge & 1.869 & & 2.135 & 2.305 & 2.135 & 2.305 \\
\hline Top-top & 1.879 & & 2.239 & 2.239 & 2.239 & 2.238 \\
\hline $\begin{array}{l}\text { One bridge } \\
\text { and one top } \\
\left(\mathrm{O}^{33}-\mathrm{C}^{7}\right)\end{array}$ & 1.865 & & 2.211 & 2.243 & 2.280 & 2.294 \\
\hline $\begin{array}{l}\text { One bridge } \\
\text { and one top } \\
\left(\mathrm{O}^{33}-\mathrm{C}^{11}\right)\end{array}$ & & 1.875 & 2.2100 & 2.200 & 2.227 & 2.321 \\
\hline
\end{tabular}

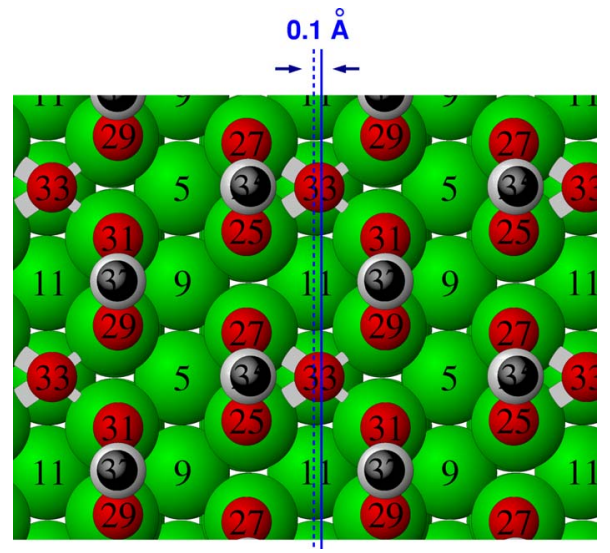

FIG. 8. (Color online) $\mathrm{Cu}$, green; $\mathrm{O}$, red; $\mathrm{C}$, gray; and $\mathrm{H}$, dark gray. Displacement of additional oxygen for two formate molecules in bridge positions and an oxygen atom in a $(2 \times 2)$ unit cell $(0.25$ ML oxygen-precovered surface). The $\mathrm{O}^{33}$ is displaced by $0.1 \AA$ from the hollow site toward $\mathrm{Cu}^{13}$ and $\mathrm{Cu}^{17}$. The oxygen atoms $\mathrm{O}^{29}$ and $\mathrm{O}^{31}$ are on top of the mentioned copper atoms. $\mathrm{H}^{35}$ and $\mathrm{H}^{37}$ are slightly tilted toward the $\mathrm{O}^{33}$ atom.

mate adsorption geometries. This is not surprising since the $\mathrm{Cu}$ atoms participating in the formate binding are also involved in the binding of the extra oxygen.

For a characterization of the effect of the preadsorbed oxygen on the formate-formate interaction, one has to compare the adsorption energies of the formate- $\mathrm{Cu}(110)$ system "high coverage" with and without additional oxygen (considering both molecules in bridge positions). The difference of the adsorption energy per formate is given by

$$
\begin{aligned}
0.25 & {\left[E_{\mathrm{Cu}(110)^{0.25 M L O}}^{2 \text { formate }}-\left(E_{\mathrm{Cu}(110)^{0.25 M L O}}+4 E_{\text {formate }}^{\text {single }}\right)\right] } \\
& -0.25\left[E_{\mathrm{Cu}(110)}^{2 \text { formate }}-\left(E_{\mathrm{Cu}(110)}+4 E_{\text {formate }}^{\text {single }}\right)\right]=\Delta E_{2},
\end{aligned}
$$

where the first bracket represents the negative binding energy of formate on the oxygen-precovered $\mathrm{Cu}(110)$ surface and the second one is the negative binding energy of formate on the $\mathrm{Cu}(110)$ surface without oxygen. $E_{\mathrm{Cu}(110)^{0.25 M L O}}^{2 \text { formate }}$ is the energy of the two formate molecules on the oxygen-precovered $\mathrm{Cu}(110)$ slab, $E_{\mathrm{Cu}(110)}^{2 \text { formate }}$ is the energy of the two formate molecules on the $\mathrm{Cu}(110)$ system, $E_{\mathrm{Cu}(110)^{0.25 M L O}}$ is the energy of the oxygen-precovered $(0.25 \mathrm{ML}) \mathrm{Cu}(110)$ slab, $E_{\mathrm{Cu}(110)}$ is the energy of the clean $\mathrm{Cu}(110)$ slab, and $E_{\text {formate }}^{\text {single }}$ is the energy of a single gas-phase formate molecule. Our results for the total energies of the different $\mathrm{Cu}$ surfaces (with and without oxygen) yield the following binding energies per formate molecule: $E_{\mathrm{Cu}(110) \text {-oxygen,formate }}^{\text {binding }}=-3.0221 \mathrm{eV}$ and $E_{\mathrm{Cu}(110), \text { formate }}^{\text {binding }}=-3.5101 \mathrm{eV}$, i.e., a positive adsorption energy difference, $\Delta E_{2}=+0.4879 \mathrm{eV}$ per formate molecule in favor of the clean $\mathrm{Cu}$ surface. This means that the oxygen does not increase the attractive interaction between the adsorbed formate molecules. But again we would like to point out that we tested the equilibrium configurations with and without oxygen at $T=0$. The effect of the adsorbed oxygen might be more important for reducing the barrier for adsorption of the second formate molecule in the $(2 \times 2) \mathrm{Cu}(110)$ surface cell. 
In fact, due to the presence of oxygen, a different reaction path for the adsorption of formate from gas-phase formic acid opened up: instead of releasing $\mathrm{H}_{2}$ when the acid form of the molecules are adsorbed, with the additional oxygen, water can be formed. This is indeed experimentally observed. ${ }^{13}$ A theoretical investigation of the kinetics has to be left to future investigations due to the very high computational demands.

\section{Comparison of adsorption energies and enthalpies}

In this section, we compile the energy difference due to the adsorption of formate molecules on $\mathrm{Cu}(110)$ for different coverages and conformations. The simplest measure is the adsorption energy (per molecule) starting from preformed free formate molecules in the gas phase. This is given by

$$
(1 / 2 n)\left[E_{\text {system }}-\left(E_{\mathrm{Cu}-\text { surface }}+2 n E_{\text {formate }}^{\text {single }}\right)\right]=E_{\text {ads }},
$$

where $E_{\text {system }}$ is the slab energy of the formate-copper-surface system, $E_{\mathrm{Cu} \text {-surface }}$ represents the slab energy of the copper surface without and/or with additional oxygen, and $n$ is the number of formate molecules in the $(2 \times 2)$ unit cell $(n=1$ for low coverage and $n=2$ for high coverage). The extra factor of $1 / 2$ is due to the fact that our slab contains two identical surfaces.

This adsorption energy includes the following contributions, all of which we calculated separately: (1) the energy due to the conformational change of the adsorbed molecules and due to the interactions between the molecules constituting the molecular layer [this is the packing energy $E_{\text {packing }}$, which can be defined as the energy necessary to bring the formate molecules from the free gas phase into a $(2 \times 2)$ array structure in the gas phase], (2) the interaction energy of the molecular layer with the copper surface (the formation of the $\mathrm{O}-\mathrm{Cu}$ bonds), and (3) the energy due to the relaxation of the copper surface under the molecular layer.

In addition, we calculated the adsorption (reaction) enthalpy at $T=0\left(\Delta H_{T=0}^{a d s}\right)$, which is defined as the difference between the sum of total energies of the products (formatecopper-surface system plus $\mathrm{H}_{2} / \mathrm{H}_{2} \mathrm{O}$ ) minus the sum of total energies of the reactants (formic acid and copper surface without or with additional oxygen) according to

$$
\begin{aligned}
& (1 / 2 n)\left[\left(E_{\text {system }}+n E_{\mathrm{H}_{2} / \mathrm{H}_{2} \mathrm{O}}\right)-\left(E_{\mathrm{Cu}-\text { surface }}+2 n E_{\text {formic-acid }}^{\text {single }}\right)\right] \\
& =\Delta H_{T=0}^{\text {ads }} .
\end{aligned}
$$

The reaction enthalpy, $\Delta H_{T=0}^{a d s}$, is the sum of the adsorption energy $\left(E_{a d s}\right)$, the energy necessary to break the oxygenhydrogen bond in the carboxylic group, and the energy due to the formation of the $\mathrm{H}_{2} / \mathrm{H}_{2} \mathrm{O}$ molecule.

The results are summarized in Table X. Our data $\left(E_{a d s}\right.$ and $\left.\Delta H_{T=0}^{a d s}\right)$ suggest that the high-coverage adsorption of formate molecules on $\mathrm{Cu}(110)$ should be the most stable configuration. The analysis of the packing energies shows that an attractive interaction between molecules in a $(2 \times 2)$ array structure in the gas phase exists. This attractive interaction is even increased in the case of high coverage (see also the difference in the adsorption energies for low and high coverages and $\left.\Delta E_{1}>0\right)$. This observation is in contradiction
TABLE X. 1, low coverage (one molecule per unit cell); 2, high coverage and 3, high coverage on the oxygen-precovered surface (two molecules per unit cell). The energies are given in $\mathrm{eV}$ per formate molecule.

\begin{tabular}{lccc}
\hline \hline System & $E_{a d s}$ & $\Delta H_{T=0}^{a d s}$ & $E_{\text {packing }}$ \\
\hline 1 & -3.390 & -0.307 & -0.057 \\
2 & -3.510 & -0.429 & -0.076 \\
3 & -3.022 & -0.278 & -0.067 \\
\hline \hline
\end{tabular}

with the experimental suggestion that a repulsive interaction exists between adsorbed molecules, because in the absence of the oxygen on the copper surface the high-coverage system cannot be clearly identified.

However, as mentioned above, the information on the reaction enthalpy is not sufficient to judge the possibility of a reaction. The reaction barriers (activation energies) decisively determine the probability of a reaction at finite temperatures.

We would like to offer some speculative ideas for contributions to the barriers in different situations. For the reaction pathways between a $\mathrm{Cu}$ surface (with and without preadsorbed oxygen) and formic acid, there are several contributions to the energy barriers, one of which is always the breaking of the oxygen-hydrogen bond of the carboxylic group. In the absence of oxygen on the $\mathrm{Cu}(110)$ surface, experiments show that the low-coverage adsorption pattern [one formate molecule in the $(2 \times 2)$ surface unit cell] is fully established, but high coverage [two formate molecules in the $(2 \times 2)$ surface unit cell] cannot be achieved by long exposure. ${ }^{13}$ One can easily imagine that, in order to adsorb an additional formate on the surface, the approaching formic acid molecule has to approach the already adsorbed formate very closely. Then the interaction between the $\pi$ systems of the two molecules comes into play, i.e., the highest occupied molecular orbital (HOMO)-lowest unoccupied molecular orbital (LUMO) interaction, which is known to be sensitively dependent on the nature of the $\pi$ systems involved and on the geometry of approach. ${ }^{49}$ Here we expect a rather strong repulsive interaction between the $3 \pi$ system of the carboxylate group (- $\mathrm{COO})$ of the adsorbed formate molecule and the $2 \pi$ system of the $\mathrm{C}=\mathrm{O}$ group of the approaching formic acid, which increases the effective energy barrier for the adsorption.

There are other examples where the HOMO-LUMO interaction between the adsorbed and approaching molecules does not prevent high-coverage adsorption on the clean copper surface: oxalic acid (which is formed by replacing in the formic acid the hydrogen atom which binds to the carbon atom by another carboxylic group) is known to form a lowcoverage configuration with upright adsorption geometries on the clean $\mathrm{Cu}(110)$ surface, which turns into a highcoverage well-ordered $(2 \times 2)$ structure upon long exposure. ${ }^{48}$ The only difference to the formic acid and/or formate case is that here the HOMO-LUMO interaction is determined by the $5 \pi$ system of the adsorbed oxalate molecule and the $4 \pi$ system of the approaching oxalic acid molecule. Apparently due to the larger spatial extent of the $\pi$ 
systems, in this case, the interaction is not so repulsive and the adsorption of the second oxalic acid molecule can take place.

In the case of preadsorbed oxygen on the copper surface, the high-coverage structure of the formate is immediately achieved without the low coverage as a precursor. ${ }^{13}$ This can be understood because there is a very different reaction path with a low barrier. The hydrogen atoms detaching from the formic acid molecules react with a preadsorbed oxygen atom to form water. This very reactive path allows two formic acid molecules to approach very closely (with the $\mathrm{C}=\mathrm{O}$ double bonds at the distant ends of the molecules), and the resulting two formate molecules can simultaneously bind to the $\mathrm{Cu}$ surface.

\section{SUMMARY}

We have investigated the adsorption geometry and stability of various configurations of formate on the $\mathrm{Cu}(110)$ surface. For all configurations, we find that the formate molecules are adsorbed with the molecular plane perpendicular to the $\mathrm{Cu}(110)$ surface.

For low coverage [one molecule in the $(2 \times 2)$ unit cell], we find that the bridge position (each oxygen of the carboxylate group binds to a single copper atom so that the carboxylate group forms a bridge between two nearest-neighbor copper atoms along the $[1 \overline{1} 0]$ direction) is the stable configuration. The $\mathrm{Cu}$ surface atoms which are not involved in the binding to oxygen atoms show inward relaxations as on the clean $\mathrm{Cu}(110)$ surface. In contrast, nearly no relaxation relative to the ideal unrelaxed $\mathrm{Cu}(110)$ surface is found for the copper atoms which form the bonds with $\mathrm{O}$ atoms.

At high coverage [two molecules in the $(2 \times 2)$ unit cell], the most stable configuration is the one with both molecules in bridge positions. The $\mathrm{Cu}(110)$ surface atoms show small outward relaxations overcompensating the first interlayer contraction of the clean surface. The geometries of both formate molecules are quite similar to that of the molecule at low coverage.

Also in the case of high-coverage formate adsorption on the oxygen-precovered $\mathrm{Cu}(110)$ surface, we find that the stable configuration is the one with both molecules in bridge positions. A large outward relaxation of the copper surface layer is found. The molecular geometry of the formate molecules does not change significantly and is similar to that of the previously discussed systems. The extra oxygen atom (the $0.25 \mathrm{ML}$ oxygen) is only slightly displaced from the hollow site position. This oxygen atom binds more strongly to the second-layer $\mathrm{Cu}$ atom than to the first-layer atoms.

The $\mathrm{Cu}-\mathrm{O}$ bond length is practically the same in all configurations. It does not depend on the coverage and agrees well with the experimentally measured one. ${ }^{12}$ The additional oxygen adsorption does not influence the bond length of the oxygen atoms of the carboxylate group with the first layer of the $\mathrm{Cu}$ surface, but rather the adsorption energy. The main geometrical changes due to the presence of oxygen are in the first interlayer relaxations. With increasing coverage, the first $\mathrm{Cu}$ surface layer relaxes toward the positions corresponding to the unrelaxed (110) surface, and for the oxygen-precovered surface, the inward relaxation for the clean $\mathrm{Cu}(110)$ surface is overcompensated and turns into a large outward relaxation.

From our calculation, we conclude that an attractive interaction between the adsorbed molecules exist. We have discussed several contributions to a high-energy barrier for the adsorption of additional formate molecules onto the formatecovered $\mathrm{Cu}$ surface: detachment of the $\mathrm{H}$ atom from the formic acid and the HOMO-LUMO repulsion between the $\pi$ systems of formic acid and formate. This may prevent a stable high-coverage configuration on the clean $\mathrm{Cu}$ surface. This situation can be reversed if the system finds it possible for the energy barrier to be lowered by a very reactive partner like preadsorbed oxygen.
${ }^{1}$ R. Raval, Curr. Opin. Solid State Mater. Sci. 7, 67 (2003).

${ }^{2}$ S. M. Barlow and R. Raval, Surf. Sci. Rep. 50, 201 (2003).

${ }^{3}$ V. Humblot, S. Haq, C. Muryn, W. A. Hofer, and R. Rava, J. Am. Chem. Soc. 124, 503 (2002).

${ }^{4}$ D. S. Martin, R. J. Cole, and S. Haq, Phys. Rev. B 66, 155427 (2002).

${ }^{5}$ D. L. Adams, H. B. Nielsen, and J. N. Andersen, Surf. Sci. 128, 294 (1983)

${ }^{6}$ K. C. Waugh, Catal. Today 15, 51 (1992).

${ }^{7}$ F. M. Leibsle, Surf. Sci. 311, 45 (1994).

${ }^{8}$ M. Bowker, S. Poulston, R. A. Bennet, P. Stone, A. H. Jones, S. Haq, and P. Hollins, J. Mol. Catal. A: Chem. 131, 185 (1998).

${ }^{9}$ M. Bowker, E. Rowbotham, F. M. Leibsle, and S. Haq, Surf. Sci. 349, 97 (1996).

${ }^{10}$ M. Bowker, S. Poulston, R. A. Bennet, and P. Stone, Catal. Lett. 56, 77 (1998).

${ }^{11}$ A. Puschmann, J. Haase, M. D. Crapper, C. E. Riley, and D. P. Woodruff, Phys. Rev. Lett. 54, 2250 (1985).
${ }^{12}$ D. P. Woodruff, C. F. McConville, A. L. D. Kilcoyne, Th. Lindner, J. Somers, M. Surman, G. Paolucci, and A. M. Bradshaw, Surf. Sci. 201, 228 (1988).

${ }^{13}$ S. Poulston, R. A. Bennett, A. H. Jones, and M. Bowker, Phys. Rev. B 55, 12888 (1997).

${ }^{14}$ P. Stone, S. Poulston, R. A. Bennet, Nicola J. Price, and M. Bowker, Surf. Sci. 418, 71 (1998).

${ }^{15}$ S. L. Silva, A. A. Patel, T. M. Pham, and F. M. Leibsle, Surf. Sci. 441, 351 (1999).

${ }^{16} \mathrm{~S}$. Poulston, A. Jones, R. A. Bennet, and M. Bowker, Surf. Sci. 377-379, 66 (1997).

${ }^{17}$ J. R. B. Gomes and J. A. N. F. Gomes, Surf. Sci. 432, 279 (1999).

${ }^{18}$ J. Phillips, F. M. Leibsle, A. J. Holder, and Todd Keith, Surf. Sci. 545, 1 (2004).

${ }^{19}$ J. P. Perdew, K. Burke, and M. Ernzerhof, Phys. Rev. Lett. 77, 3865 (1996); 78, 1396 (1997); 80, 891 (1998).

${ }^{20}$ W. Kromen, Ph.D. thesis, RWTH-Aachen, 2001.

${ }^{21}$ R. Berger, S. Blügel, A. Antons, Wi. Kromen, and K. Schroeder, 
Proceedings of the NIC-Workshop Molecular Dynamics on parallel Computers, Jülich, 8-10 February 1999 (World Scientific, Singapore, 2000), pp. 185-198.

${ }^{22}$ L. Kleinman and D. M. Bylander, Phys. Rev. Lett. 48, 1425 (1982).

${ }^{23}$ P. E. Blöchl, Phys. Rev. B 50, 17953 (1994).

${ }^{24}$ J. D. Pack and H. J. Monkhorst, Phys. Rev. B 16, 1748 (1977).

${ }^{25}$ A. Rauk, D. Yu, and D. A. Armstrong, J. Am. Chem. Soc. 116, 8222 (1994).

${ }^{26}$ D. Feller, E. S. Huyser, W. T. Borden, and E. R. Davison, J. Am. Chem. Soc. 105, 1559 (1983).

${ }^{27}$ A. Rodriguez and C. T. Campbell, Surf. Sci. 183, 449 (1987).

${ }^{28}$ D. W. Bullettt and W. G. Dawson, Prog. Surf. Sci. 25, 275 (1987).

${ }^{29}$ D. W. Bullettt and W. G. Dawson, Vacuum 38, 389 (1988).

${ }^{30}$ W. H. Kirchhoff, J. Farren, and J. W. Linnett, J. Chem. Phys. 42, 1410 (1965).

${ }^{31}$ P. Y. Ayala and H. Schlegel, J. Chem. Phys. 108, 7560 (1998).

${ }^{32}$ A. Rauk, D. Yu, P. Borowski, and B. Roos, Chem. Phys. 197, 73 (1995).

${ }^{33}$ J. L. F. Da Silva, K. Schroeder, and S. Blügel, Phys. Rev. B 69, 245411 (2004).

${ }^{34}$ T. Rofach, K. P. Bohnen, and K. M. Ho, Surf. Sci. 286, 66 (1993).

${ }^{35}$ S. Y. Liem, G. Kresse, and J. H. R. Clarke, Surf. Sci. 415, 194 (1998)
${ }^{36}$ A. D. Becke, J. Chem. Phys. 98, 5648 (1993).

${ }^{37}$ M. H. Jamroz and J. Cz. Dobrowolski, J. Mol. Struct. 565-566, 475 (2001).

${ }^{38}$ S. Hoyau and G. Ohanessian, Chem. Phys. Lett. 280, 266 (1997).

${ }^{39}$ L. A. M. M. Barbarosa and P. Sautet, J. Am. Chem. Soc. 124, 6639 (2001).

${ }^{40}$ B. Hammer and J. K. Norskov, in Chemisorption and Reactivity of Supported Clusters and Thin Films, edited by R. M. Lambert and G. Pacchioni (Kluwer Academic, Dordrecht, 1997), pp. 285-351.

${ }^{41}$ R. D. Felice and A. Selloni, J. Chem. Phys. 120, 4906 (2003).

${ }^{42}$ M. Preuss, W. G. Schmidt, and F. Bechstedt, Phys. Rev. Lett. 94, 236102 (2005).

${ }^{43}$ H. Dürr, Th. Fauster, R. Schneider, and Surf. Sci. 244, 237 (1991).

${ }^{44}$ M. Bader, A. Puschmann, C. Ocal, and J. Haase, Phys. Rev. Lett. 57, 3273 (1986).

${ }^{45}$ R. Feidenhans'1, F. Grey, R. L. Johnson, S. G. J. Mochrei, J. Bohr, and M. Nielsen, Phys. Rev. B 41, 5420 (1990).

${ }^{46}$ T. Schimizu and M. Tsukada, Surf. Sci. 295, 1017 (1993).

${ }^{47}$ Y. Uehara, T. Matsumoto, and S. Ushioida, Solid State Commun. 119, 671 (2001).

${ }^{48}$ D. S. Martin, R. J. Cole, and S. Haq, Surf. Sci. 539, 171 (2003).

${ }^{49}$ I. Fleming, Frontier Orbitals and Organic Chemical Reactions (Wiley, London, 1978). 